\title{
THE MEDIATION ROLE OF ORGANIZATIONAL SLACK AND INNOVATION CLIMATE ON THE EFFECT OF PERCEIVED ORGANIZATIONAL SUPPORT IN ACADEMIC PERFORMANCE
}

\author{
Dilshad TAHA MEERO \\ Duhok University, Kurdistan Rejoin - Iraq
}

(Received: September 27, 2020; Accepted for Publication: November 16, 2020)

\begin{abstract}
ABSRACT
The main objective of this research is to examine the mediation role of both organizational slack and innovation climate on the effect of perceived organizational support on academic performance at the colleges of Duhok University by using path analysis. The research reviews the contributions of researchers on the subjects of perceived organizational support (POS), organizational slack (OS), innovation climate (IC), and academic performance (AP). Constructing on previous studies, a set of hypotheses are formulated to express the effect of the POS, OS, IC variables on AP variable. A sample of 181 lecturers were selected to verify research hypotheses which have been proposed. Finally, the main conclusions of the research are presented.

The results of the investigation reveal that the organizational slack and innovation climate variables mediates the influence between the perceived organizational support and the academic performance and that the indirect effect between the perceived organizational support and the academic performance was stronger than the direct influence between them.
\end{abstract}

KEYWORDS: perceived organizational support, organizational slack, innovation climate, academic performance.

\section{INTRODUCTION}

$\mathbf{T}$ he academic staff is the most important elements in the operations at the academic institutions, their academic performance related to the success of that institutions. Empirical studies analyze the impact of some factors on AP, and others investigate the POS, OS, and IC with another factor too. In our research, we try to discover the impact relation between those three variables (POS, OS, and IC) on AP from academic staff's view.

An effective innovation climate in academic institutions is the climate that provides the tools for the academic staff to operate and achieve excellence in their performance in teaching, researching, and others scientific work. Some researchers believe that successful innovation requires a climate that developed and implement of innovative ideas; a climate in which employees can receive messages of innovation and try new work strategies in the organization (Soken \& Barnes, 2014).

The perceived organizational support subject correlate with some norms between both organization and employees such as respect, commitment, payment and promotion, and access to information and other forms of aid needed to better carry out one's job. The norm of reciprocity allows employees and organization to reconcile these distinctive orientations. According to (Rhoades and Eisenberger, 2002) the employees showed a consistent pattern of agreement with statements concerning whether the organization appreciated their contributions and would treat them favorably or unfavorably in differing circumstances. Employees who are emotionally committed to the organization show heightened performance, reduced absenteeism, and a lessened likelihood of quitting their job (Mathieu and Zajac, 1990; Meyer and Allen, 1997; Mowday et al., 1982).

The word 'slack' often carries a negative nuance, for example, the basic reason for implementing organizational downsizing is to eliminate organizational slack and thereby improve firm performance. However, theoretical discussions do not unambiguously support such an idea. While many studies deal with the issues of organizational slack and its effect on firm performance, there seems to be no consensus on the directionality of the effect of slack on 
performance. Theories based on agency costs tend to suggest the negative impact of organizational slack on firm performance, but traditional organization theories such as the behavioral theory of the firm argue for the positive association between slack and performance (Lee, 2012). Organizational slack is generally defined as the excess resources available to the organization, such as financial slack resources and slack in human resources.
For example, organizational slack includes redundant employees, unused capacity, unnecessary capital expenditures, increases in the margins and revenues (Nohria and Gulati, 1996).

The purpose of this research is to provide a model to demonstrate and examines direct and indirect relations between the four variables (Figure

1).

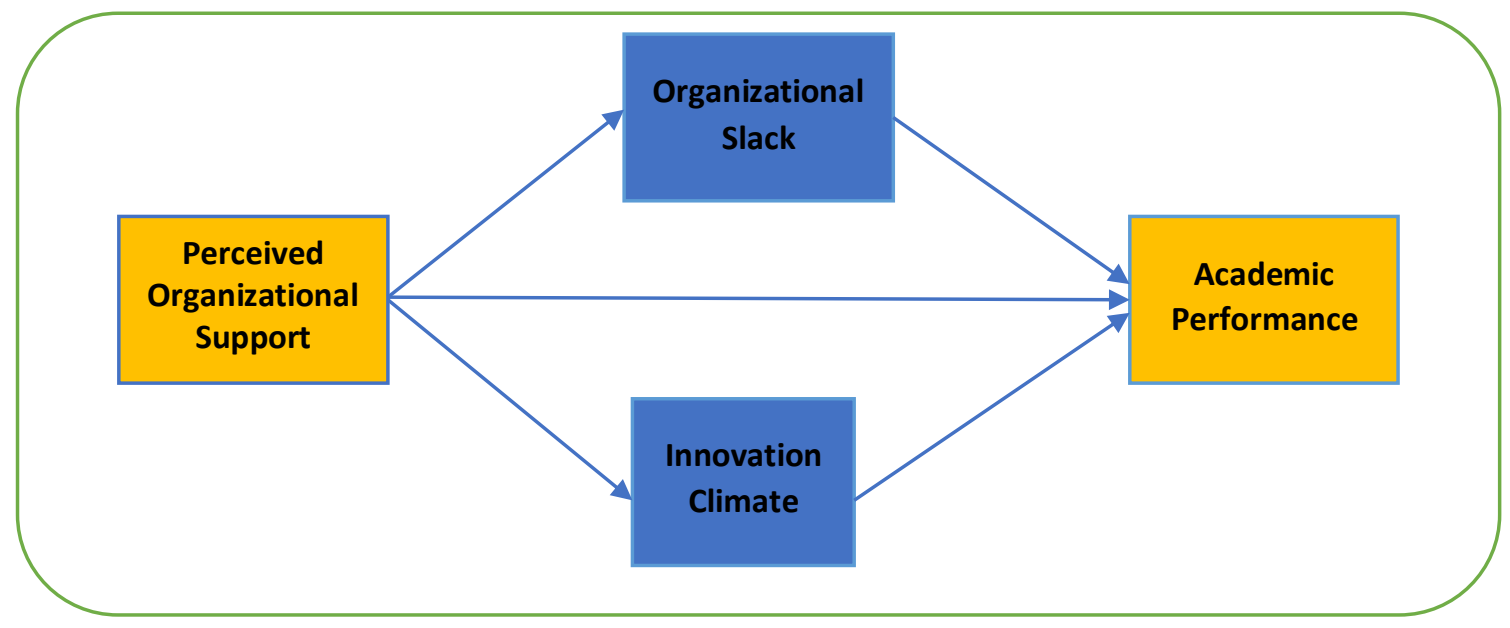

Fig. (1): Research Model

\section{LITERATURE REVIEW}

\subsection{Perceived Organizational Support}

Organizational support refers to any action adopted by the organization or its representatives that indicates concern for the worker's welfare. Perceived organizational support (POS) is the worker's general perception of the way in which the organization appreciates his contribution, is committed to him, and sees to his wellbeing; for example, the worker feels that the organization will be on his side in the case of personal problems (Eisenberger et al., 1986). Researchers (Johlke et al., 2002) explain according to social exchange theories that when workers feel a high degree of support by the organization, they will feel a commitment to reward the organization with their loyalty and positive behaviors (Holsblat, 2014).

According to organizational support theory, the development of POS is encouraged by employees' tendency to assign the organization humanlike characteristics (Eisenberger et al., 1986). Levinson (1965) noted that actions taken by agents of the organization are often viewed as indications of the organization's intent rather than attributed solely to the agents' personal motives. This personification of the organization, suggested Levinson, is abetted by the organization's legal, moral, and financial responsibility for the actions of its agents; by organizational policies, norms, and culture that provide continuity and prescribe role behaviors; and by the power the organization's agents exert over individual employees. On the basis of the organization's personification, employees view their favorable or unfavorable treatment as an indication that the organization favors or disfavors them. Social exchange theorists argue that resources received from others are more highly valued if they are based on discretionary choice rather than circumstances beyond the donor's control. Such voluntary aid is welcomed as an indication that the donor genuinely values and respects the recipient (Blau, 1964; Cotterell, Eisenberger and Speicher, 1992; Eisenberger, Cotterell and Marvel, 1987; Gouldner, 1960). Thus, organizational rewards and favorable job conditions such as pay, promotions, job enrichment, and influence over organizational policies contribute more to POS if the employee 
believes that they result from the organization's voluntary actions, as opposed to external constraints such as union negotiations or governmental health and safety regulations (Eisenberger et al., 1986; Eisenberger, Cummings, Armeli, and Lynch, 1997; Shore and Shore, 1995). Because supervisors act as organizational agents, the employee's receipt of favorable treatment from a supervisor should contribute to POS. The strength of this relation depends on the degree to which employees identify the supervisor with the organization, as opposed to viewing the supervisor's actions as idiosyncratic (Rhoades and Eisenberger, 2002).

Organizational support theory also addresses the psychological processes underlying consequences of POS. First, on the basis of the reciprocity norm, POS should produce a felt obligation to care about the organization's welfare and to help the organization reach its objectives. Second, the caring, approval, and respect connoted by POS should fulfill socioemotional needs, leading workers to incorporate organizational membership and role status into their social identity. Third, POS should strengthen employees' beliefs that the organization recognizes and rewards increased performance (i.e., performance-reward expectancies). These processes should have favorable outcomes both for employees (e.g., increased job satisfaction and heightened positive mood) and for the organization (e.g., increased affective commitment and performance, reduced turnover). An appealing feature of organizational support theory is that it provides clear, readily testable predictions regarding antecedents and outcomes of POS along with specificity of assumed processes and ease of testing these processes empirically (Rhoades and Eisenberger, 2002).

\subsection{Organizational Slack}

Organizational researchs has increasingly focuse $\mathrm{d}$ on why managers accumulate,

maintain, and deploy certain types of resources as a method to achieve organization success. Early work in the area suggested that organizational slack directly impacts firm performance

(Bourgeois, 1981; Bourgeois and Singh, 1983).

However, for than two decades the related research has presented conflicting views about how organizational slack specifically impact firm performance. Other research argue that organizational slack buffers the firm from rapid changes in its externa
1 environment (Bansal, 2003) (Walfald et al., 2010).

Also, organizational slack has been extensively discussed in organizational theory and strategic management literature. Although a consistently used definition has not been reached, a commonly accepted one is that organizational slack encompasses available, recoverable, and potential slack (Bourgeois, and Singh, 1983). Organizational slack, which comprises these three components, is commonly viewed as excess resources that play the role of "buffer" between organizations and external contingencies (Cheng and Kesner, 1997). Business managers can deploy organizational slack to respond to unexpected demand (Sharfman, and Dean, 1997) and successfully adapt to pressures from internal and external forces (Xu et al., 2015). Organizational slack has been defined as a cushion of actual or potential resources which allow an organization to adapt successfully to internal pressures for adjustment or to external pressures for change in policy, as well as to initiate changes in strategy with respect to external environment.

Organizational slack represents potentially utilizable resources that can be redeployed to achieve the firm's goals (Daniel et al., 2004). It can be divided into absorbed slack (such as underutilized capacity) and unabsorbed slack (such as currently uncommitted cash flows and untapped lines of credit) (Nohria and Gulati,

1996). By definition, absorbed slack is not easy to be redeployed, and unabsorbed

slack is more flexible and more easily redeploy (Ping et al., 2009).

Organizational slack has been defined in the literature in different ways. For example, Cyert and March (1993) defined organizational slack as "the disparity between the resources available to the organization and the payments required to maintain the coalition". Similarly, Bourgeois (1981) defined organizational slack as resources in excess of what is required for the efficient operation of a firm. Also, Nohria and Gulati (1996) defined organizational slack as "the pool of resources in an organization that is in excess of the minimum necessary to produce a given level of organizational output". Another research defines organizational slack as "the resources readily available to an organization that are in excess of the minimum necessary to produce a given level of organizational output as well as the resources that are recoverable from being embedded in the firm" (Heping, 2013). 
Organizational slack can take many forms, including excess financial resources (Cheng and Kesner, 1997; Sharfman et al., 1988; Nystrom et al., 2002), excess inventory, excess machine capacity (Sharfman et al., 1988), and excess labor (Sharfman et al., 1988; Nystrom et al., 2002; Kidd and Richter, 2001). Two opposing views of the role of slack in an organization can be found in the literature. One perspective views slack as positive. Slack provides excess resources and allows managerial controls to be relaxed, which allows managers more freedom in deciding which activities a firm may pursue (Geiger and Cashen, 2002). Slack also encourages a firm to engage in more risky projects because the excess resources afforded by slack enables the organization to absorb the failure associated with potentially uncertain outcomes (Geiger and Cashen, 2002; Nystrom et al., 2002). Slack has also been found to encourage creativity and experimentation (Stock et al., 2015).

\subsection{Innovation Climate}

Innovation climate is a subset of organizational climate and it can play a vital role in promoting creativity and innovation among employees (Amabile, et al., 1996). A research by Price water house Coopers (2007) concluded that building an innovation climate is one of the key capabilities that characterized the more successful organizations.

Anderson and West (1998) examined the climate for innovation at team level they presented evidence that support for innovation at a team level was a significant predictor of overall innovation at the organizational level.

The research of Isaksen and Akkermans (2011), confirmed that workplace climate was important in influencing the level of creativity at an individual and organizational level, and that perceptions of time pressure as a pure climate variable moderated the influence of environment on creativity and innovation.

McAlindon (2004) defined the characteristics that can be used to measure the innovation climate as: risk-taking, rewards, empowering, objective measurement, feedback, turbulence, interdependence, decentralization and cosmopolitan.

Isaksen and Tidd (2006), argue that climate of innovation and creativity is the climate that supports the development, assimilation and utilization of new and different approaches, practices and concepts, it is also the climate which promotes the generation, consideration and use of new products, services, and ways of working.

Sarros et al., (2008) in their research examines the relationships between transformational leadership with innovation climate and the extent to which a competitive, performance-oriented organizational culture mediates this relationship.

\subsection{Academic Performance}

Academic performance is affected by numerous factor and many researchers conducted detailed studies about the factors contributing student performance at different research levels, these factors may be classified into academic or non-academic factors. Considine and Zappala (2002) noticed that social status positively affects the student test score in examination.

In the research of Oregon State University (2003) on graduate admissions that normal measures of educational potential and academic performance such as high school grade point average (GPA) scores showed only $30 \%$ of the deviation in initial or starting (first) year at college.

According to Minnesota (2007) the higher education performance is depending upon the academic performance of graduate students.

Zakaria et al. (2011) conducted a survey which showed that environmental factors have an impact on the academic performance of the student.

In the research of Erdem (2013) found a significant relationship between students' achievement and factors such as preparatory school attendance, high school graduated from, father's education level, and class attendance.

Ruby and David (2014) argue that many factors influence the academic performance of the student. The research model is mainly focused on exploring various indicators that have an effect on the academic performance of the students, the research result shows the impact of various factors affecting the students of higher education system, the extracted information that describes student performance can be stored as intelligent knowledge for decision making to improve the quality of education in institutions.

Gajghat et al (2017) research suggest that there are so many opinions about the impact of these factors affecting the academic performance, some academicians think that personal characteristics, learning habits are more 
important whereas others argue that previous academic background and college environmental factors are more related with the students' performance. But there is substantial evidence that the views expressed by different stakeholders are not always consistent. Numbers of papers have been illustrated on the related topic and different multi-variable models have been developed to predict students' performance.

\section{METHODOLOGY:}

\section{1 Sample and Data Collection:}

The field of applying the research was in the colleges of the University of Duhok, where the research population represents all the lecturers or academic staff in the respondent colleges. A random sample of lecturers working in these colleges was selected to represent the sample of the research. Two hundred questionnaires were distributed to the sample of the academic staff, (189) questionnaire were returned which represented the response rate of $(94.5 \%)$ from the distributed forms. The number of forms valid for the analysis were (181) form, which accounted for $(90.5 \%)$ of the distributed forms, and therefore the size of the final sample of the research was (181). Table (1) explain the sample and the distribution of the questionnaire.

Table (1): The sample and the distribution of the questionnaire

\begin{tabular}{cccccc}
\hline \multirow{2}{*}{ No. } & Colleges of & \multicolumn{3}{c}{ Questionnaire No. } & Response \\
\cline { 3 - 5 } & & Distributed & Collected & Valid & $\%$ \\
\hline 1 & Law \& Political Sciences & 20 & 19 & 18 & $90 \%$ \\
\hline 2 & Humanities & 20 & 20 & 19 & $95 \%$ \\
\hline 3 & Administration \& economic & 20 & 20 & 20 & $100 \%$ \\
\hline 4 & Engineering & 20 & 19 & 19 & $95 \%$ \\
\hline 5 & Dentistry & 20 & 17 & 16 & $80 \%$ \\
\hline 6 & Science & 20 & 20 & 19 & $95 \%$ \\
\hline 7 & Physical education \& Sport & 20 & 20 & 18 & $90 \%$ \\
\hline 8 & Sciences & 20 & 18 & 18 & $90 \%$ \\
\hline 9 & Basic Education & 20 & 20 & 19 & $95 \%$ \\
\hline 10 & Languages & 20 & 16 & 15 & $75 \%$ \\
\hline & Pharmacy & 200 & 189 & 181 & $90.5 \%$ \\
\hline
\end{tabular}

\subsection{Research Tool:}

The questionnaire was the main tool in the collection of field data, which included information about personal characteristics of the participants such as gender, age, academic degree, and service duration. Forty items were used to examine the correlation between variables of the research. Respondents in this research rated each item on a 3-point Likert scale ranging from disagree (1) to agree (3). The questionnaire included (10) statements to measure each variable in the research, as shown in table (2).

Table (2): The Questionnaire Contents

\begin{tabular}{ccc}
\hline Seq. & Variables & N of Items \\
\hline 1 & Personal Demographic & 4 \\
\hline 2 & Perceived Organizational Support & 10 \\
\hline 3 & Organizational Slack & 10 \\
\hline 4 & Innovation Climate & 10 \\
\hline 5 & Academic Performance & 10 \\
\hline
\end{tabular}

\subsection{The Sample Characteristics:}

More than $56.4 \%$ of the respondents were male, approximately $35.4 \%$ of them with age between 30 - 40 years, about $54.2 \%$ holding master degree, and $47.5 \%$ had an employment duration more than 10 years. Table (3) show details of frequencies and percentages about the respondent demographic characteristics.

Dilshad.Meero@uod.ac 
Table (3): The Demographic Characteristics

\begin{tabular}{cccc}
\hline Characteristics & Demographics & Freq. & $\%$ \\
\hline \multirow{2}{*}{ Gender } & Male & 102 & 56.4 \\
\cline { 2 - 4 } & Female & 79 & 43.6 \\
\hline \multirow{2}{*}{ Age } & Less Than 30 Year & 38 & 21.0 \\
\cline { 2 - 4 } & 30 - less than 40 year & 64 & 35.4 \\
\cline { 2 - 4 } & 40 - less than 50 year & 46 & 25.4 \\
\cline { 2 - 4 } & 50 year and more & 33 & 18.2 \\
\hline \multirow{2}{*}{ Academic Degree } & PHD & 82 & 45.3 \\
\cline { 2 - 4 } & Master & 99 & 54.7 \\
\hline Service & 1 less than 5 year & 40 & 23.2 \\
\cline { 2 - 4 } Duration & 5 less than 10 year & 55 & 30.3 \\
\cline { 2 - 4 } & 10 year and more & 86 & 100.0 \\
\hline & Total & 181 & \\
\hline
\end{tabular}

\subsection{Research Problem}

Academics are the most important resources in the universities and in academic institutions, also their performance leads to the success or failure of those institutions. Some of the previous studies analyze the impact of some factors on academic's performance, and others investigate the perceived organizational support, organizational slack, and innovation climate with other factors. In this research, we try to investigate the effect and relation between perceived organizational support and academic performance through the mediation role of organizational slack, and innovation climate. In the universities of the Kurdistan region, there is a need to develop the performance of the academic staff by preparing the necessary requirements for this, including the perceived organizational support, which helps to achieve progress in the outputs of our universities and put it in the ranks of regional and global universities. Based on this point, the research problem can be formulated in the following questions:

1. What are the attitudes of academic staff at the University of Duhok towards research variables?

2 . Is there any significant relation and effect between perceived organizational support and academic performance at the University of Duhok?

3. Is there any mediation role for organizational slack and innovation climate on the effect of perceived organizational support in academic performance?

\subsection{Research Objectives}

This research aims to investigate the following goals:
1. Measuring the level of POS, OS, IC, and AP among the respondents at the colleges of university of Duhok.

2. Diagnosing the nature of the relation between POS, OS, IC, and AP.

3. Identify the mediation role of OS and IC on the effect of POS in AP.

4. Providing a set of suggestions to the colleges leaders at university of Duhok towards the variables of the research.

\subsection{The Significance of the Research}

The significance of the research can be highlighted by focusing on some academic aspects, as it is an extension of knowledge in the fields of organization theory specialization and the solutions and treatments that the researched colleges are exposed to in the two fields of how to raise the levels of their academic staff and depending on perceived organizational support, as well as the importance of the organizational slack and innovation climate as a moderators variables affecting the relationship between perceived organizational support and academic staff. The significance of the research also lies in the information provided to decision-makers in the colleges of Duhok university on the results of field diagnosis for the research variables.

\subsection{Research Hypotheses:}

The following hypotheses were conducted to test the relation between the research variables at the 0.05 level of significant:

Hypothesis 1: The level of perceived organizational support, organizational slack, and innovation climate is positively related to the academic performance.

Hypothesis 2: The perceived organizational support has a significant direct effect on the academic performance. 
Hypothesis 3: The of perceived organizational support has a significant indirect effect through the mediating role of the organizational slack on the academic performance.

Hypothesis 4: The of perceived organizational support has a significant indirect effect through the mediating role of the innovation climate on the academic performance.

\section{RESULTS AND DISCUSSION}

\subsection{Questionnaire Tests:}

The questionnaire was prepared based on the theoretical perspective. The terms were adjusted to suit the field studied. They were tested in a number of statistical methods as follows:

\subsubsection{Measuring Reliability:}

The Cronbach Alpha coefficient was used to confirm the ability of the questionnaire to achieve the required reliability according to the statistical criteria. The highest value of the reliability coefficient was found for the perceived organizational support $(0.850)$ while the reliability values of the organizational slack, innovation climate and academic performance variables was $(0.788),(0.804)$, and $(0.811)$, So that the overall reliability of all questionnaire items was (0.825), which confirms the reliability required for the questionnaire compared to the standard value of reliability (0.70) (Hair et al., 2010). and these results are shown in table (4).

Table (4): The Reliability Coefficient

\begin{tabular}{ccc}
\hline Variables & N of Items & Cronbach's Alpha \\
\hline POS & 10 & 0.850 \\
\hline OS & 10 & 0.788 \\
\hline IC & 10 & 0.804 \\
\hline AP & 10 & 0.811 \\
\hline Total Q. Items & 40 & 0.825 \\
\hline
\end{tabular}

\subsubsection{Testing the Research data:}

For the purpose of verifying that the current research data are analyzed according to Parametric tests or Nonparametric tests, they are subjected to a number of statistical analysis conditions related to the distinction between them, the results of testing normal distribution (Z) was calculated by Shapiro-Wilks method to verify the availability of normal distribution in the data of the research. The results of the analysis in table (5) showed that all calculated Z values for the variables of the research were less than the tabulated $\mathrm{Z}$ value of the research, indicating that the current research data takes the form of the required natural distribution. Also, the sample size for this research was more than (30) items, so we can conclude that the current research data has passed those conditions and therefore it is possible to apply the parametric tests to verify the scientific research hypotheses.

Table (5): The Normality Test

\begin{tabular}{cccccc}
\hline Variables & Mean & STD & Calculated Z & Tabulated Z & Sig. \\
\hline POS & 2.256 & 0.495 & 0.960 & 3.070 & 0.193 \\
\hline OS & 1.906 & 0.761 & 0.666 & 3.158 & 0.089 \\
\hline IC & 2.212 & 0.458 & 0.978 & 2.965 & 0.177 \\
\hline AP & 2.143 & 0.501 & 0.991 & 2.967 & 0.146 \\
\hline
\end{tabular}

$N=181$

\subsection{Descriptive Statistics}

The results in table (6) show that there are different levels of agreement among the respondents on the contents of all the items of the POS, OS, IC, and AP variables according to the mean which was (2.25), (1.91), (2.21), (2.14) with standard deviation of (0.495), (0.761),
(0.428), and (0.501) respectively. According to coefficient of variance which was (21.9\%), (39.9\%), (20.7\%), and (23.4\%) respectively, this indicate that there is a high level of agreement in the opinions of the respondent sample toward IC variable, while the low level of agreement was toward OS variable. 
Table (6): The Descriptive Statistics

\begin{tabular}{cccc}
\hline Variables & Means & STD & Coefficient of Variance \\
\hline POS & 2.256 & 0.495 & $21.9 \%$ \\
\hline OS & 1.906 & 0.761 & $39.9 \%$ \\
\hline IC & 2.212 & 0.458 & $20.7 \%$ \\
\hline AP & 2.143 & 0.501 & $23.4 \%$ \\
\hline
\end{tabular}

\subsection{Test Hypothesis 1:}

The correlation analysis results in the table (7) Indicate that there are significant levels of positive relationship between the POS, OS, IC, and AP variables, where the correlation coefficient between them was (0.696), (0.258), and $(0.711)$ at different levels of significant $(0.01),(0.05)$, and $(0.01)$ respectively, this indicates that the better the levels of variables POS, OS, and IC, the greater the enhance of the levels of academic performance. This results support the hypothesis one which refer that the level of perceived organizational support, organizational slack, and innovation climate is positively related to the academic performance.

Table (7): The Correlations Between Variables

\begin{tabular}{|c|c|c|c|c|c|}
\hline & riables & POS & OS & IC & AP \\
\hline \multirow[t]{2}{*}{ POS } & Pearson Correl. & 1 & -0.187 & $0.549^{* *}$ & $0.696^{* *}$ \\
\hline & Sig. (2-tailed) & & .095 & 0.000 & .000 \\
\hline \multirow[t]{2}{*}{ OS } & Pearson Correl. & -0.187 & 1 & 0.089 & $0.258^{*}$ \\
\hline & Sig. (2-tailed) & .095 & & .124 & 0.017 \\
\hline \multirow[t]{2}{*}{ IC } & Pearson Correl. & $0.549^{* *}$ & 0.089 & 1 & $0.711^{* *}$ \\
\hline & Sig. (2-tailed) & 0.000 & .124 & & 0.000 \\
\hline \multirow[t]{2}{*}{ AP } & Pearson Correl. & $0.696^{* *}$ & $0.258^{*}$ & $0.711^{* *}$ & 1 \\
\hline & Sig. (2-tailed) & .000 & 0.017 & 0.000 & \\
\hline
\end{tabular}

** Correlation is significant at the 0.01 level (2-tailed)

* Correlation is significant at the 0.05 level (2-tailed)

\subsection{Test Hypothesis 2:}

The results of the simple regression analysis in table (8) showed that there is a direct effect of the perceived organizational support on the academic performance, based on the value of the calculated level of significance (0.007) which is less than the default level of the research (0.05). And this is confirmed by the value of calculated (F), which amounted to $(32,855)$, which is greater than its tabulated value of (3.894) with degrees of freedom $(1,179)$. This result can be evidenced by the parameters of following:

- The value of $\left(\mathrm{B}_{0}\right)$ and according to the regression equation indicates that there is an appearance of academic performance with value (0.623) when the value of the perceived organizational support is equal to zero, indicating that the academic performance acquires part of its characteristics from the perceived organizational support.

- According to the value of the $\left(\mathrm{B}_{1}\right)$, which was valued (0.696), this mean that the change of one unit in the perceived organizational support will be accompanied by a change in the academic performance by (0.696). This is a high indicator that can be used to explain the effect of POS as independent variable on AP as dependent variable.

- The value of the $\mathrm{R}^{2}$ reached (0.484) and this indicates that the change in the perceived organizational support explain $(48.4 \%)$ of the change in academic performance, and the remaining $(51.6 \%)$ of the change in the organizational slack due to other factors not included in the current research model. 
Table (8): The Simple Regression Model

\begin{tabular}{cccccccc}
\hline Model & R Square & df & F Cal. & F Tab. & $B_{0}$ & $B_{1}$ & Sig. \\
\hline 1 & 0.484 & $1-179$ & 32.855 & 3.894 & 0.623 & 0.696 & .007 \\
\cline { 2 - 7 } & \multicolumn{7}{c}{ Dependent Variable: AP } \\
\cline { 2 - 6 } & \multicolumn{7}{c}{ Predictors: POS } \\
\hline
\end{tabular}

From the results of regression analysis, the hypothesis 2 is accepted, which states that the perceived organizational support has a significant impact on the academic performance at the level of 0.05 .

\subsection{Test Hypothesis 3:}

The third hypothesis stated that the perceived organizational support has a significant indirect effect through the mediating role of the organizational slack on the academic performance. The results in table (9) according to AMOS V. 23 program show that the coefficient of the path from perceived organizational support to academic performance is equal to 0.079 which is significant at the level of 0.011 , that is, the perceived organizational support affect the academic performance. Whereas the path coefficient from the perceived organizational support to the organizational slack was 0.120 , which is not significant at the level of 0.069 which indicates that the perceived organizational support does not affect the organizational slack. The coefficient of the path from the organizational slack to the academic performance is 0.840 which is significant at the level of 0.002 and this indicates that the organizational slack affects the academic performance. Based on extrapolation of the results, there is a significant effect of the perceived organizational support in the academic performance and through the organizational slack where the effect came at a level of $(0.000)$ and the coefficient of indirect path was equal to (0.101) which is greater than the coefficient of direct path between the perceived organizational support and the academic performance of (0.079). This indicates that the indirect effect is better than the direct effect.

According to the quality fitness indicators, the current structural model is characterized by a good of fitness according to the values of ChiSquare and the fitness quality indicators which was (356.771), (0.04), (0.968).

Table (9): Path Analysis for POS, OS, and AP

\begin{tabular}{|c|c|c|c|c|c|}
\hline Path & Path Coefficient & Sig. & $\begin{array}{c}\text { Chi - } \\
\text { Square }\end{array}$ & RMSEA & AGFI \\
\hline POS --- AP & 00.79 & 0.011 & 356.771 & 0.04 & 0.968 \\
\hline POS --- OS & 0.120 & 0.069 & & & \\
\hline OS ---- AP & 0.840 & 0.002 & & & \\
\hline POS --- OS ---- AP & $0.12 * 0.84=0.101$ & 0.000 & & & \\
\hline
\end{tabular}

From the results of path analysis, the hypothesis 3 is accepted, which states that the perceived organizational support has a significant indirect impact through the mediating role of the organizational slack on the academic performance.

\subsection{Test Hypothesis 4:}

The fourth hypothesis stated that the of perceived organizational support has a significant indirect impact through the mediating role of the innovation climate on the academic performance. The results in table (10) according to AMOS V. 23 program show that the coefficient of the path from perceived organizational support to academic performance is equal to (0.079) which is significant at the level of (0.011), that is, the perceived organizational support affect the academic performance. Whereas the path coefficient from the perceived organizational support to the innovation climate was (0.258), which is significant at the level of (0.003) which indicates that the perceived organizational support affect the innovation climate. The coefficient of the 
path from the innovation climate to the academic performance is $(0.661)$ which is significant at the level of (0.000) and this indicates that the innovation climate affects the academic performance. Based on extrapolation of the results, there is a significant effect of the perceived organizational support in the academic performance and through the innovation climate where the effect came at a level of (0.000) and the coefficient of indirect path was equal to
(0.170) which is greater than the coefficient of direct path between the perceived organizational support and the academic performance of (0.079). This indicates that the indirect effect is better than the direct effect.

According to the quality fitness indicators, the current structural model is characterized by a good of fitness according to the values of ChiSquare and the fitness quality indicators which was (742.808), (0.01),

(0.985).

Table (10): Path Analysis for POS, IC, and AP

\begin{tabular}{|c|c|c|c|c|c|}
\hline Path & Path Coefficient & Sig. & $\begin{array}{c}\text { Chi - } \\
\text { Square }\end{array}$ & RMSEA & AGFI \\
\hline POS --- AP & 00.79 & 0.011 & 742.808 & 0.01 & 0.985 \\
\hline POS --- IC & 0.258 & 0.003 & & & \\
\hline IC ---- AP & 0.661 & 0.000 & & & \\
\hline POS --- IC --- AP & $0.258 * 0.661=0.170$ & 0.000 & & & \\
\hline
\end{tabular}

From the results of path analysis, the hypothesis 4 is accepted, which states that the perceived organizational support has a significant indirect impact through mediating role of the innovation climate on the academic performance.

\subsection{Findings:}

1. The colleges at the Duhok university suffer from the phenomenon of organizational slack according to the views of the respondent sample. 2. One of the most important causes of organizational slack is that the colleges selects the lecturers without regulations for professional competence and qualifications required.

3 . It has been found that the predict of the future expansion of the recruitment of additional human and material resources to open new scientific colleges and departments is not one of the reasons for the organizational slack. Overrecruitment and social reasons, such as alleviation of unemployment, are also not the causes of organizational slack.

4. It was found that there are significant relationship and impact between the perceived organizational support and the academic performance, this indicate that the higher level of perceived organizational support will lead to a higher level of academic performance.

5. It was found that the organizational slack variable mediates the influence between the perceived organizational support and the academic performance and that the indirect effect between the perceived organizational support and the academic performance was stronger than the direct influence between them. 6. It was found that the innovation climate variable mediates the influence between the perceived organizational support and the academic performance and that the indirect effect between the perceived organizational support and the academic performance was stronger than the direct influence between them.

\subsection{Suggestions:}

1. The administration of the investigated colleges should endeavor to create an appropriate innovation climate that enables their employees to realize that they are making efforts to provide organizational support and to make them performing their teaching and researching tasks.

2. The university administration should work to guide the investigated colleges to alleviate the levels of organizational slack found in those colleges by: Appointment of academic staff in an objective manner, based on the actual need for the academic work requirements. And Selecting lecturers according to the professional competence and qualifications required in order to achieve higher levels of the educational process and reduce administrative corruption and favoritism in recruitment.

3. Utilizing the abilities of the academic staff that are idle and untapped by opening training courses and workshops that contribute to 
providing them with new skills and knowledge to help alleviate the phenomenon of organizational slack in the researched colleges.

4. The investigated colleges at Duhok university should endeavor to exert all possible efforts to achieve stability and job security for academic as one of the means that achieve innovation climate that lead to improving the academic performance.

5. As a future research, we suggest that the same variables may be studied on the management level of the colleges and university.

\section{REFERENCES}

Amabile, T. M., Conti, R., Coon, H., Lazenby, J., and Herron, M., 1996, Assessing the work environment for creativity, Academy of Management Journal, Vol.39 No. 5, pp. 1154- 1184.

Anderson, N. R., and West, M. A., 1998, Measuring climate for work group innovation: Development and validation of the team climate inventory. Journal of Organizational Behavior, 19, 235-258.

Bansal, P., 2003, From issues to action: The Importance of the individual concerns and organizational values in responding to natural environmental issues, Organization Science, Vo. 14, No. 5, PP. 510 - 527.

Blau, P. M., 1964, Exchange and power in social life, John Wiley \& Sons Inc., New York, USA.

Bourgeois, L. J., 1981, On the measurement of organizational slack, Academy of Management Review, Vol. 6, No. 1, pp. 29-39, 1981.

Cheng, J.L.C. and Kesner, I.F., 1997, Organizational slack and response to environmental shifts: The impact of resource allocation patterns, Journal of Management, Vol. 23, No. 1, pp. 1-18.

Cheng, J.L.C.; and Kesner, I.F., 1997, Organizational slack and response to environmental shifts: The impact of resource allocation patterns, Journal of Management, Vol.1, No. 23, 1-18.

Considine, G. \& Zappala, G., 2002, Influence of social and economic disadvantage in the academic performance of school students in Australia, Journal of Sociology, 38, 129-148

Cotterell, N., Eisenberger, R., and Speicher, H., 1992, Inhibiting effects of reciprocation wariness on interpersonal relationships, Journal of Personality and Social Psychology, 62, 658-668.

Cyert, R. M. and March, J. G., 1993, A Behavioral Theory of the Firm, Prentice-Hall: Englewood Cliffs, NJ, USA.

Daniel, F.; Lohrke, F.; Fornaciari, C.; and Turner, 2004, Slack resources and firm performance: A meta-analysis, Journal of Business Research, Vol. 57, No. 6, PP. 565 - 574.

Erdem, H. E., 2013, A Cross-Sectional Survey in Progress on Factors Affecting Students Academic Performance at a Turkish University, Procedia Social and Behavioral Sciences, vol. 70, pp. 691-695, 2013.

Eisenberger, R., Cotterell, N., and Marvel, J., 1987, Reciprocation ideology, Journal of Personality and Social Psychology, 53, 743-750.

Eisenberger, R., Cummings, J., Armeli, S., and Lynch, P., 1997, Perceived organizational support, discretionary treatment, and job satisfaction, Journal of Applied Psychology, 82, 812-820.

Eisenberger, R., Huntington, R., Hutchison, S., and Sowa, D. Perceived organizational support, Journal of Applied Psychology, 71, 500-507. 1986.

Gajghat R. H.; Handa, C. C.; and Himte R. L., 2017, Factors Influencing academic Performance of the students at university Level Exam: A Literature Review, International Journal of Research in Engineering and Technology, Volume 6, Issue 5, May.

Geiger, S.W. and Cashen, L.H., 2002, A multidimensional examination of slack and its impact on innovation, Journal of Managerial Issues, Vol. 14, No. 1, pp. 68-84. 
Gouldner, A. W., 1960, The norm of reciprocity: A preliminary statement, American Sociological Review, 25, 161-178.

Hair JR, Joseph F., Black, William C., Babin, Barrys J.\& Andersen, Rolph E., 2010, Multivariate data analysis,7th ed., Upper Saddle River, PrenticeHall, New Jersey

Heping, Z., 2013, Organizational Slack and the Marketing Performance of Information Technology Firms International Journal of Innovation, Management and Technology, Vol. 4, No. 2, April.

Holsblat, R., 2002, The Relationship between Commitment to the Organization, Perceived Organizational Support, Job Satisfaction, and Organizational Citizenship Behavior of Teachers, American Journal of Educational Research, 2014, Vol. 2, No. 12, 11751181.

Isaksen, S., and Tidd, J., (2006), Meeting the Innovation Challenge: Leadership for Transformation and Growth, John Wiley \& Sons Inc., New York, USA.

Johlke, M. C., Stamper, C. L. and Shoemaker, M. E., 2002, Antecedents to boundary spanner perceived organizational support," Journal of Managerial Psychology, 17, 116-128.

Kidd, J. and Richter, F.J., 2001, The hollowing out of the workforce: what potential for organizational learning?, Human Systems Management, Vol. 20 , pp. 7-18.

Lee, S., 2012, Corporate Governance, Financial Slack and Firm Performance: A Comparative Research between US and UK, Seoul Journal of Business, Volume 18, Number 1.

Levinson, H., 1965, Reciprocation: The relationship between man and organization, Administrative Science Quarterly, 9, 370-390.

McAlindon, H. R., 2004, Innovation Climate, Information Technology
Leadership in Higher Education, (1), pp.73-82.

Mathieu, J. E., and Zajac, D., 1990, A review and meta-analysis of the antecedents, correlates, and consequences of organizational commitment, Psychological Bulletin, 108, 171-194.

Meyer, J. P., and Allen, N. J., 1997, Commitment in the workplace: Theory, research and application. Thousand Oaks, CA: Sage, USA.

Mike, W. P.; Li, Y.; Xie, E.; and Su, Z., 2009, CEO duality, organizational slack, and firm performance in China, Asia Pacific Journal of Management, Online Springer Science, July.

Mowday, R. T., Porter, L. W., \& Steers, R. M. (1982). Organizational linkages: The psychology of commitment, absenteeism, and turnover, San Diego, CA: Academic Press, USA.

Nohria, N., \& Gulati, R., 1996, Is slack good or bad for innovation?. Academy of Management Journal, 39: 1245-1264.

Nystrom, P.C., Ramamurthy, K., and Wilson, A.L., 2002, Organizational context, climate and innovativeness: adoption of imaging technology, Journal of Engineering and Technology Management, Vol. 19, No. 3, 4, pp. 221-247.

Price Water house Cooper, (2007), Compete and Collaborate, the 11th Annual Global CEO Survey, New York.

Rhoades, L. and Eisenberger, R., 2002, Perceived Organizational Support: A Review of the Literature, Journal of Applied Psychology, Vol. 87, No. 4, PP. 698-714.

Ruby, J., and David, K., 2014, A Research Model on the Impact of Various Indicators in the Performance of Students in Higher Education, International Journal of Research in Engineering and Technology, Volume 3 Issue, 5 May.

Sarros, J. C.; Cooper B. K., and Santora J. C., 2008, Building a Climate for Innovation Through Transformational 
Leadership and Organizational Culture, Journal of Leadership \& Organizational Studies, Volume 15, Number 2 November, PP. 145-158

Sharfman, M.; and Dean, J., 1997, Flexibility in decision making: Informational and ideological perspectives, Journal of Management, Vol.1, No. 34, 191-217.

Sharfman, M.P., Wolf, G., Chase, R.B., and Tanskik, D.A., 1988, Antecedents of organizational slack, Academy of Management Review, Vol. 13, No. 4, pp. 601-614.

Shore, L. M., \& Shore, T. H., 1995, Perceived organizational support and organizational justice. In R. S. Cropanzano \& K. M. Kacmar (Eds.), Organizational politics, justice, and support: Managing the social climate of the workplace (pp. 149-164). Westport, CT: Quorum.

Soken, N. H. \& Barnes, B. K. (2014), "What kills innovation? Your role as a leader in supporting an innovative culture",
Industrial and Commercial Training, Vol. 46 No. 1, pp. 7- 15.

Stock, G. N.; Greis, N. P.; and Fischer, W. A., 2015, Organizational slack and new product time to market, https://decisionsciences.org/wpcontent/uploads/2017/11/p671812.pdf. Wefald, A. J.; Katz, J. P.; Downey, R. G.; and Rust, K. G., 2010, organizational Slack, Firm Performance, and the Role of Industry, Journal of Managerial Issues, Vol. 22, No. 1, Spring, PP. 70 87.

Xu, E.; Yang, H.; Quan, J.M.; Lu, Y. Organizational slack and corporate social performance: Empirical evidence from China's public firms. Asia Pac. J. Manag. 2015, 32, 181198.

Zakaria, Z.; Kassim, R. A.; Mohamad, A.; and Buniyamin, N., 2011, The impact of environment on engineering students' academic performance: A pilot research," in Engineering Education (ICEED), 2011 3rd International Congress, 2011. 
يوخته

مهرهما سهرهكى يا قيّ قه كولينى ئهنجامدانا خاندنهكى يه لسهر كارتيّكرنا رولى نافبهركى يا لاوازبوونا

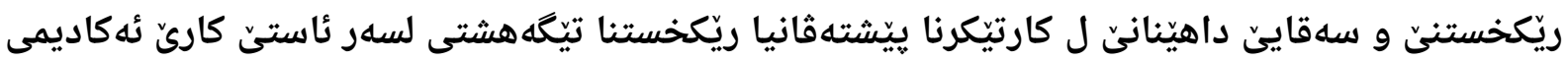

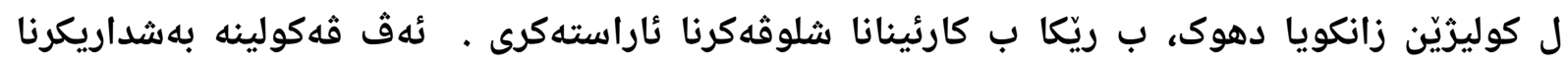

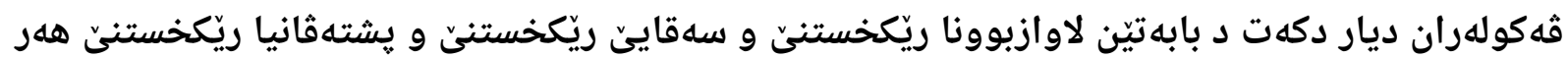
وهسا ئاستى ئهكاديمى، ل سهر بنگههي هندهى ثه كولينيّن بهرى نوكه ل سهر هاتينه ئهنجامدان. كومهكا

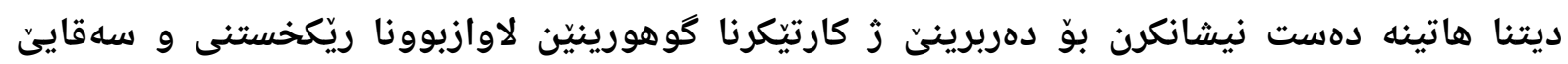

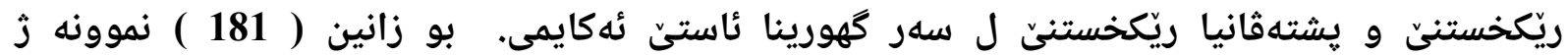

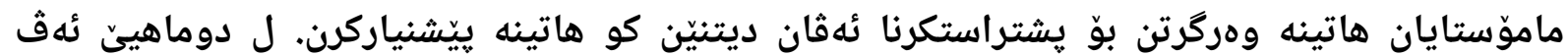

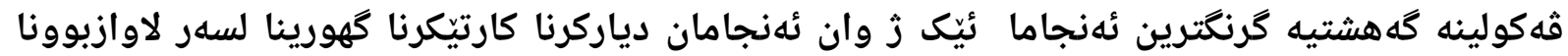

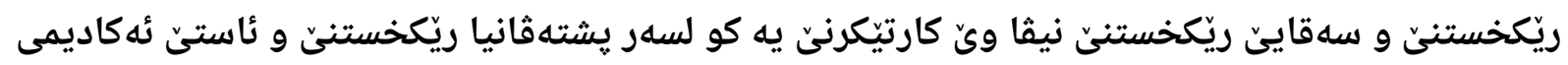

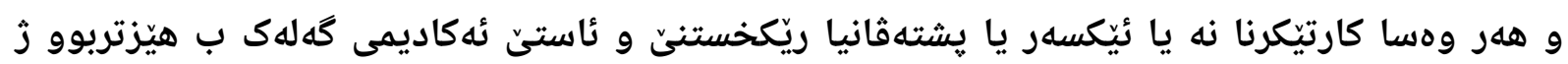

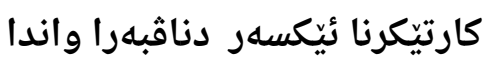
يه يڤّين دهربرينَّ : لاوازيا ريّكخستنى ، سهقايت ريّكخستنى ، يشته ثانيا ريكخستنى ، ئاستى ئهكاديمى

الهدف الرئيسي من هذا البحث هو عمل دراسة عن تاثير الدور الوسيط للترهل التنظيمي و المناخ

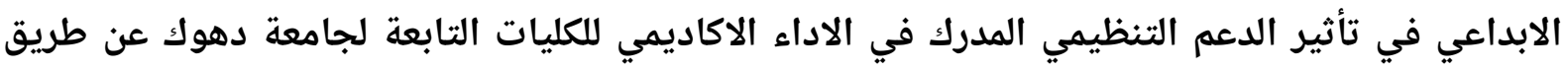
استخدام تحليل المسار ، يستعرض البحث مساهمات الباحثين في موضوعات الترهل التنظيمي و المناخ

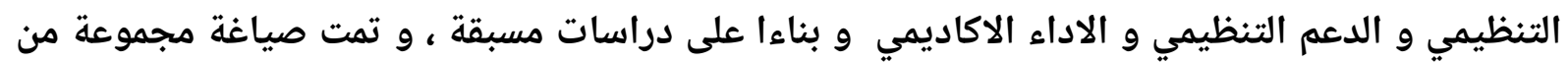

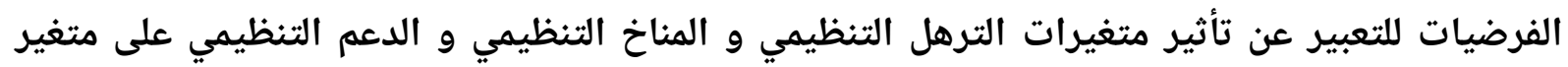
الاداء الاكاديمي و لقد تم اختيار ( 181 ) عينة من التدريسيين كنموذج للتحقق من الفرضيات التي تم اقتراحها ، و في النهاية لقد توصل الدراسة الى تقديم اهم الاستنتاجات ومنها كشفت هذه الدراسة على ان تاثير التغيرات في الترهل التنظيمي و المناخ التنظيمي بمتوسط التاثير بين الدعم التنظيمي و الاداء

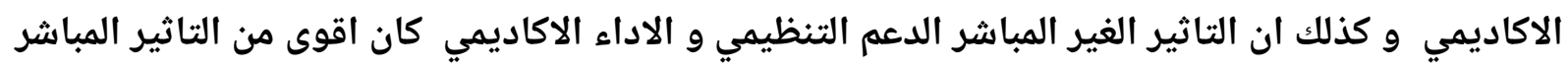

